\title{
Diagnostic and therapeutic approach to post-traumatic tracheobronchial injuries
}

\author{
Angelo Carretta ${ }^{1,2, *}$, Paola Ciriaco ${ }^{1}$, Alessandro Bandiera ${ }^{1}$, Giampiero Negri ${ }^{1,2}$
}

${ }^{1}$ Department of Thoracic Surgery, San Raffaele Scientific Institute, 60 - 20132 Milan, Italy

${ }^{2}$ School of Medicine, Vita-salute San Raffaele University, 60 - 20132 Milan, Italy

\section{*Correspondence}

angelo.carretta@hsr.it

(Angelo Carretta)

\begin{abstract}
Post-traumatic tracheobronchial lesions are associated with high mortality unless adequately diagnosed and treated. They may be caused by blunt and penetrating trauma, although iatrogenic lesions are also increasingly observed. An early and accurate diagnosis significantly impacts the results of treatment. Radiological assessment with computed tomography is highly accurate, but bronchoscopy remains the gold standard technique in the diagnosis of airway trauma and plays an important role in determining the therapeutic approach. For a long time, surgery has been considered the treatment of choice for post-traumatic airway lesions, but recent reports have shown that favourable results may also be obtained with a conservative approach, especially in the treatment of iatrogenic lesions. The indication for a conservative or surgical treatment has to be defined on the basis of a thorough clinical, radiological, and endoscopic assessment. Specific issues concerning airway management in the emergency setting and during surgical treatment must also be addressed. A multidisciplinary approach in a center with specific experience in the treatment of airway lesions is of utmost importance to obtain favourable results.
\end{abstract}

\section{Keywords}

Airway; Trauma; Surgery; Anesthesia; Conservative

\section{Introduction}

Post-traumatic lesions of the trachea and bronchi are associated with significant morbidity and mortality unless promptly recognized and treated $[1,2]$. The actual incidence of lesions due to blunt or penetrating trauma is underestimated, since a large number of patients die before a diagnosis can be obtained [3]. Bertelsen and Howitz reported a 2.8\% incidence of these lesions in post-mortem examinations [4]. In recent decades an increasing number of iatrogenic lesions due to intubation or tracheostomy has also been reported [5]. Several issues concerning the diagnosis and treatment of post-traumatic tracheobronchial lesions still have to be defined. Surgical treatment has been traditionally considered the treatment of choice for traumatic airway lesions, but in recent years conservative and endoscopic treatments have also been associated with favourable results [6-8]. Establishing clinical, radiological, and endoscopic criteria to select the most appropriate treatment is of utmost importance for obtaining favourable results. Moreover, selecting an optimal surgical and anesthesiological strategy is essential in reducing perioperative mortality. Another issue to be analyzed concerns the role of bronchoscopy in the treatment of airway lesions.

\section{Etiology and pathogenesis}

Post-traumatic airway lesions may be caused by blunt or penetrating traumatic events [9]. The site of the lesion may vary according to the pathogenesis. Direct trauma or compression of the cervical trachea against the spine may cause fracture of the laryngeal cartilages or even a complete separation of the airway, usually between the cricoid cartilage and the proximal trachea $[10,11]$. Cervical hyperextension during the trauma may also determine tears of the proximal trachea. On the other hand, about $80 \%$ of intrathoracic airway lesions due to blunt trauma are located within $2.5 \mathrm{~cm}$ of the carina [12]. Various mechanisms have been suggested to explain this finding. A sudden increase of airway pressure during chest compression while the glottis is reflexedly closed may cause laceration of membranous wall of the airway or a separation of the cartilagineous and membranous parts of the airway. Other factors include the limited mobility of the carina and the lateral traction on the pulmonary hila as the chest is antero-posteriorly compressed while the lungs move laterally with the chest cage. In most cases a combination of these mechanisms may be present, leading to complex airway lesions $[12,13]$. One of the main issues following blunt trauma concerns the frequent association with major post-traumatic lesions of the head, chest, and abdomen, which account for most of the early and late mortality and to an underestimation of the real incidence 
of airway lesions [14]. They also therefore must be carefully assessed during the diagnostic and intraoperative evaluation. Penetrating airway trauma, mostly due to knives or gunshot wounds, may involve any part of the tracheobronchial tree [15]. However, penetrating injuries of the intrathoracic trachea and main bronchi are seldom recognized, since they are usually associated with lesions of the heart and major vessels that lead to death before a diagnosis is obtained.

An increasing number of iatrogenic lesions has been reported in previous decades, and in recent reports they represent the majority of post-traumatic lesions. Accordingly, in the series analyzed by Schneider et al., about $58 \%$ of tracheobronchial lesions were iatrogenic and only $42 \%$ were due to blunt or penetrating trauma [5]. Although most iatrogenic lesions are a complication of single- or double-lumen intubation, lesions following percutaneous dilational tracheostomy (PDT), flexible or rigid bronchoscopy, and surgery are also reported. The incidence of airway lesions following singlelumen intubation is about $0.005 \%$ [16] and ranges from 0.05 to $0.26 \%$ after double-lumen intubation $[17,18]$. The pathogenetic mechanism of post-intubation airway injuries includes the inappropriate use of stylets, hyperinflation of the tube cuff, and tube repositioning with an inflated cuff $[19,20]$. Once the laceration is created, usually in the membranous part of the airway, the cuff may no longer adequately seal the airway during mechanical ventilation, and if not detected the lesion may be enlarged when the cuff is further inflated. Risk factors for the onset of iatrogenic lesions include intubation by unskilled personnel, emergency intubation, female gender, short stature, and steroid treatment [16]. Congenital or acquired intrinsic or extrinsic airway stenosis, connective tissue diseases, and Mounier-Kuhn syndrome may also increase the risk of airway lesions and should be recognized before intubation [21]. In comparison with post-traumatic lesions, which often have complex features, post-intubation iatrogenic lesions are more frequently longitudinal and involve the membranous wall of the trachea and main bronchi [11, 20, 22]. These different characteristics, along with the frequent association of lesions due to blunt or penetrating trauma with other major posttraumatic lesions, account for the relatively higher mortality of post-traumatic airway lesions compared to iatrogenic injuries.

Iatrogenic lesions may also be observed after thyroid, pulmonary, esophageal, and cardiac surgery [23, 24]. If promptly recognized these lesions are repaired during the surgical procedure, reducing the risk of further complications. Tracheobronchial lesions may also arise during flexible and rigid bronchoscopy, especially during stent positioning or dilation of airway stenosis [25]. However, although relatively frequent, lesions caused by bronchoscopic procedures usually only partially involve the tracheobronchial wall, and spontaneously heal in most cases. With the improvement of intensive care treatments, an increasing number of patients currently undergo percutaneous dilational tracheostomy (PDT). The reported incidence of airway lesions after PDT is about $1 \%$ [26]. Inadvertent puncture of the posterior tracheal wall during the manoeuvre may lead to a misplacement of the guidewire outside the tracheal lumen and even through the esophageal wall, leading to a major lesion if not promptly recognized [27]. Adequate expertise and bronchoscopic control during the procedure are strongly advised to prevent this complication, although in experienced hands a low incidence of airway lesions has been reported even without endoscopic assistance [28-30]. Knowledge of the pathogenesis and correct management of the endotracheal tube are essential for preventing iatrogenic lesions of the airway.

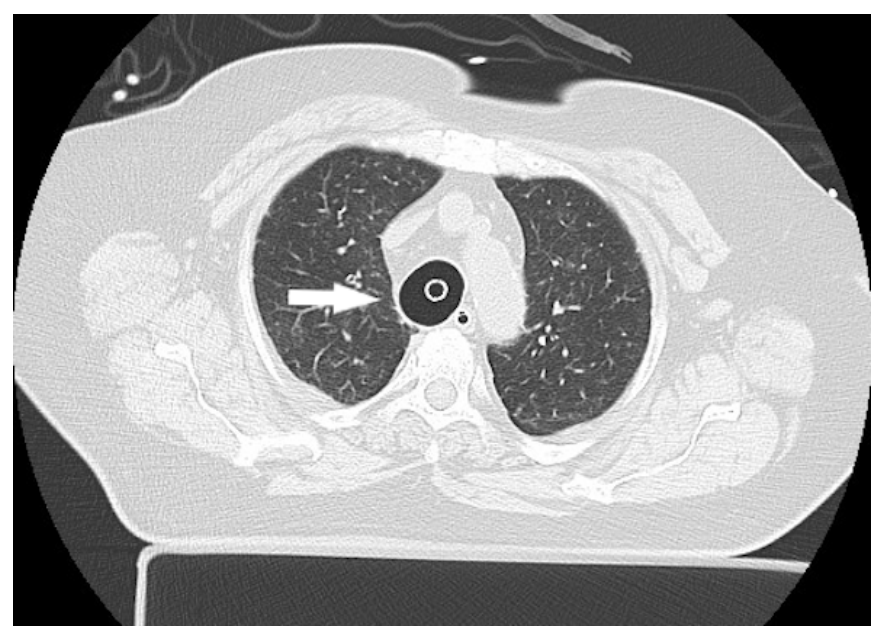

FIGURE 1. Computed tomography scan showing hyperinflated tracheal tube cuff in a patient with postintubation tracheal injury (arrow).

\section{Diagnostic approach}

A high index of suspicion is of primary importance to achieve an early and effective treatment. Clinical signs that have to be accurately observed include respiratory distress, subcutaneous emphysema, haemoptysis, voice hoarseness, stridor, and shock. In patients with penetrating injuries, exposure of the airway or presence of an air leak through the wound may be observed. Indirect signs of post-traumatic airway trauma on chest x-ray include mediastinal emphysema and persistent pneumothorax after chest tube placement [31]. The role of ultrasound in the evaluation of airway lesions is limited, although it may show indirect signs as pneumothorax and subcutaneous emphysema [32]. Displacement of the lung in the dependent part of the chest cavity may be observed on chest X-ray when a complete transection of the bronchus is present ("fallen lung sign") [33]. A radiological assessment with computed tomography (CT) significantly improves the diagnostic accuracy [31,34]. The airway lesion may be directly visualized, but more frequently indirect signs such as cervical and mediastinal emphysema, pneumothorax, or cervical and mediastinal tissue herniation inside the airway lumen are observed. Pneumoperitoneum and pneumopericardium are rarely reported $[35,36]$. An overinflated tube cuff may be a sign of a tracheal lesion, even if not associated with mediastinal emphysema (Fig. 1). This happens because the cuff of the endotracheal tube may seal the tracheal defect, and mediastinal emphysema may develop only when the cuff is deflated and the endotracheal tube repositioned. Despite the relatively high accuracy of CT scan, bronchoscopy remains the gold standard technique in the evaluation of post-traumatic tracheobronchial lesions. Flexible bronchoscopy allows for accurate assessment 
TA B L E 1. Airway control strategies in patients with post-traumatic airway lesions.

If possible, maintain spontaneous ventilation until airway control
Intubation under bronchoscopic control
Intubation with bronchoscope through laryngeal mask airway (LMA)
Emergency tracheostomy if intubation is not possible
Temporary intubation through the cervical wound if airway exposed
Cuff of the endotracheal tube positioned distal to airway lesion
Avoid cuff hyperinflation
Unilateral or bilateral endobronchial intubation in patients with carinal lesions
Extracorporeal membrane oxygenation (ECMO)

of not only location, length, and depth of the lesion but also viability of margins and presence of communication with the mediastinal or pleural space, data that are essential to correctly define the therapeutic strategy $[14,36]$. In nonintubated awake patients the laryngeal function, which may have been impaired by the trauma, may also be evaluated. Rigid bronchoscopy may be indicated to remove blood clots or foreign materials obstructing the airway, while allowing accurate examination of the lesion. Esophageal lesions, on the other hand, must be ruled out through radiological and endoscopic assessment. Data from the combined clinical, radiological, and endoscopic evaluation must be thoroughly analysed to define therapeutic indication. In particular, location, length, depth, presence of extraluminal communication, and associated laryngeal, esophageal, pulmonary, and cardiovascular lesions must be carefully considered when selecting the treatment strategy.

\section{Airway management}

Establishing a secure airway greatly contributes to reducing mortality and allowing an adequate diagnostic and therapeutic approach to be completed. Blind intubation in patients with airway injuries may widen the lesion or determine incorrect tube placement outside the tracheobronchial lumen, leading to a sudden increase of mediastinal pressure with catastrophic cardiocirculatory and respiratory impairment $[1,6]$. In spontaneously breathing patients with an adequate gas exchange, intubation should thus be delayed until bronchoscopic guidance is available. Whenever possible the patient should be intubated while spontaneously breathing or with short-acting neuromuscular blocking agents to reduce the risk of airway collapse at the level of the lesion, especially when a complete separation is present. Fiberoptic intubation, which may also be accomplished through a laryngeal mask airway (LMA), allows for safe positioning of the cuff of the tracheobronchial tube distal to the lesion while simultaneously allowing the injury to be visualized. Emergency tracheostomy is required in patients who cannot be intubated due to major maxillofacial trauma or laryngeal lesions [37]. In patients with penetrating injuries the airway may be directly exposed, and intubation through the wound may be temporarily performed, allowing the patient to be ventilated and preventing blood aspiration before a tracheostomy or translaryngeal intubation can be achieved [38, 39]. Specific problems arise when the lesion involves the distal trachea or the main bronchi near the carina, since positioning the cuff of the tracheobronchial tube beyond the lesion while maintaining bilateral ventilation may not be feasible. Selective intubation of the noninjured main bronchus may allow ventilation to be temporarily maintained while treatment is accomplished, although it may not be a viable option in patients with reduced respiratory function due to associated pulmonary lesions. The use of two small-bore endobronchial tubes inserted through a tracheostomy has also been reported in patients with lesions involving the carinal region [40, 41]. Whenever intubation or tracheostomy cannot be safely established, the use of extracorporeal membrane oxygenation (ECMO) in the emergency setting may be a lifesaving option (Table 1) [42].

\section{Endoscopic classification}

Assessment of the endoscopic characteristics of the tracheobronchial lesion plays a major role in the definition of the therapeutic strategy. In previous reports the length of the lesion was considered a main issue when the indication for conservative or surgical treatment had to be defined. According to Carbognani and Harris, only lesions shorter than $2 \mathrm{~cm}$ were suitable for a conservative treatment [43, 44]. Conversely, Ross and Massard considered that lesions up to $5 \mathrm{~cm}$ could be conservatively treated $[18,45]$. More recently, successful conservative treatment of lesions exceeding these limits has been reported, and therefore the extent of the lesion seems to have lost importance in the definition of the therapeutic strategy [8]. In fact, other features such as depth of the lesion, clinical parameters, and presence of infection have gained more relevance in the planning of treatment. Cardillo et al. proposed a four-tier classification of iatrogenic airway injuries on the basis of endoscopic and clinical criteria: lesions limited to the mucosa and submucosa without mediastinal emphysema and oesophageal injury were classified as level I. Lesions involving the muscular layer of the airway with subcutaneous or mediastinal emphysema but no oesophageal injury or mediastinitis were classifid as level II. Conversely, complete lacerations of the tracheal wall with oesophageal or mediastinal tissue herniation without oesophageal injury or mediastinitis were defined as level IIIA, while full-thickness lesions with oesophageal injury or mediastinitis were classified as level IIIB. On the basis of this classification a differentiated therapeutic approach was proposed. Conservative treatment by means of observation, antibiotic treatment, or endoscopic closure with 
TA B L E 2. Results of treatment in blunt and penetrating airway trauma.

\begin{tabular}{lccccc} 
Author (Year) & $\begin{array}{c}\text { Total No. } \\
\text { (Blunt/penetrating } \\
\text { trauma) }\end{array}$ & $\begin{array}{c}\text { Surgical } \\
\text { treatment No. pts }\end{array}$ & $\begin{array}{c}\text { Conservative } \\
\text { treatment No. pts }\end{array}$ & $\begin{array}{c}\text { Mortality of } \\
\text { surgical } \\
\text { treatment }\end{array}$ & $\begin{array}{c}\text { Mortality of } \\
\text { conservative } \\
\text { treatment }\end{array}$ \\
\hline Rossbach (1998) [7] & $32(13 / 19)$ & 32 & 0 & $2(6.2 \%)$ & - \\
\hline Cassada (2000) [1] & $18(9 / 9)$ & 18 & 0 & $1(5.5 \%)$ & 0 \\
\hline Balci (2002) [14] & $32(13 / 19)$ & 31 & 1 & $6(19.3 \%)$ & $1(100 \%)$ \\
\hline Richardson (2004) [65] & $60(46 / 14)$ & 60 & 0 & $8(13.3 \%)$ & - \\
\hline Gómez-Caro (2005) [8] & $15(13 / 2)$ & 11 & 4 & 0 & $1(25 \%)$ \\
\hline Carretta (2011) [51] & $14(7 / 7)$ & 10 & 4 & 0 & 0 \\
\hline Koletsis (2012) [36] & $15(10 / 5)$ & 15 & 0 & $1(6.6 \%)$ & - \\
\hline Lyons (2013) [15] & $22(0 / 22)$ & 22 & 0 & $1(4.5 \%)$ & 0
\end{tabular}

TA B L E 3. Results of treatment in iatrogenic airway trauma.

\begin{tabular}{lccccc} 
Author (Year) & Total No. & $\begin{array}{c}\text { Surgical treatment } \\
\text { No. Pts }\end{array}$ & $\begin{array}{c}\text { Conservative } \\
\text { treatment No. pts }\end{array}$ & $\begin{array}{c}\text { Surgical treatment } \\
\text { mortality }\end{array}$ & $\begin{array}{c}\text { Conservative } \\
\text { treatment mortality }\end{array}$ \\
\hline Gómez-Caro (2005) [8] & 18 & 2 & 16 & $1(50 \%)$ & $3(18.7 \%)$ \\
Conti (2006) [41] & 30 & 2 & 28 & $2(100 \%)$ & $4(14.2 \%)$ \\
\hline Leinung (2006) [66] & 42 & 35 & 7 & $1(2.8 \%)$ & $2(28.5 \%)$ \\
Schneider (2007) [76] & 29 & 18 & 11 & $3(16.6 \%)$ & 0 \\
Leoncini (2008) & 15 & 3 & 12 & 0 & 0 \\
Cardillo (2010) [46] & 30 & 1 & 29 & 0 & 0 \\
Carretta (2011) [51] & 36 & 20 & 16 & $1(5 \%)$ & $1(6.25 \%)$ \\
Koletsis (2012) [36] & 10 & 7 & 3 & 0 & 0 \\
Ceylan (2013) [17] & 18 & 18 & 0 & 0 & 0 \\
Herrmann (2019) [47] & 64 & 43 & 21 & $10(23.2 \%)$ & 0 \\
\hline
\end{tabular}

fibrin glue was indicated in level I and II lesions, while level IIIb lesions required surgical treatment. On the other hand, in patients with level IIIa lesions, which represented only a small part of the series analysed, indication of conservative or surgical treatment was defined after multidisciplinary evaluation [46]. It must be considered, however, that along with endoscopic features, clinical conditions and associated lesions remain a key issue in defining the therapeutic strategy. In fact, stable vital signs, adequate respiratory parameters under spontaneous or mechanical ventilation, absence of esophageal injury, minimal mediastinal fluid, nonprogressive mediastinal and/or subcutaneous emphysema, and absence of sepsis must be evaluated when considering the feasibility of a conservative treatment. Moreover, endoscopic classifications such as the one proposed by Cardillo et al. mainly refer to lesions involving the membranous wall, which are more frequently observed in patients with iatrogenic lesions. In patients with post-traumatic injuries due to blunt and particularly to penetrating trauma, which more often present complex characteristics and are associated with unstable clinical features, surgical treatment is usually more frequently indicated (Tables 2 and 3).

\section{Conservative treatment}

The role of conservative treatment has increased in recent years. A nonsurgical approach was previously considered only in the treatment of patients with a contraindication to surgical treatment or when the involvement of the tracheobronchial wall was limited [43, 44]. More recently, favourable results with this approach have also been reported in the treatment of more extensive lesions [8, 41]. Therefore, the specific role of conservative and surgical treatment in the treatment of airway trauma is a matter of debate. Miñambres et al. observed a lower mortality after conservative treatment than following surgery in patients with post-intubation lesions [16]. However, the comparative results of conservative and surgical treatment may be influenced by patient selection, since complex lesions associated with unstable clinical features are more often treated surgically. In fact, reports on conservative treatment mainly refer to the treatment of iatrogenic lesions, which are usually limited to the membranous part of the airway and not associated with other post-traumatic lesions. Candidates for conservative treatment should be clinically stable, maintain adequate respiratory parameters under spontaneous ventilation or while intubated, and have no mediastinal fluid collection, signs of infection, esophageal lesions, increasing pneumomediastinum, or persistent pneumothorax. The type of conservative treatment may be differentiated according to 


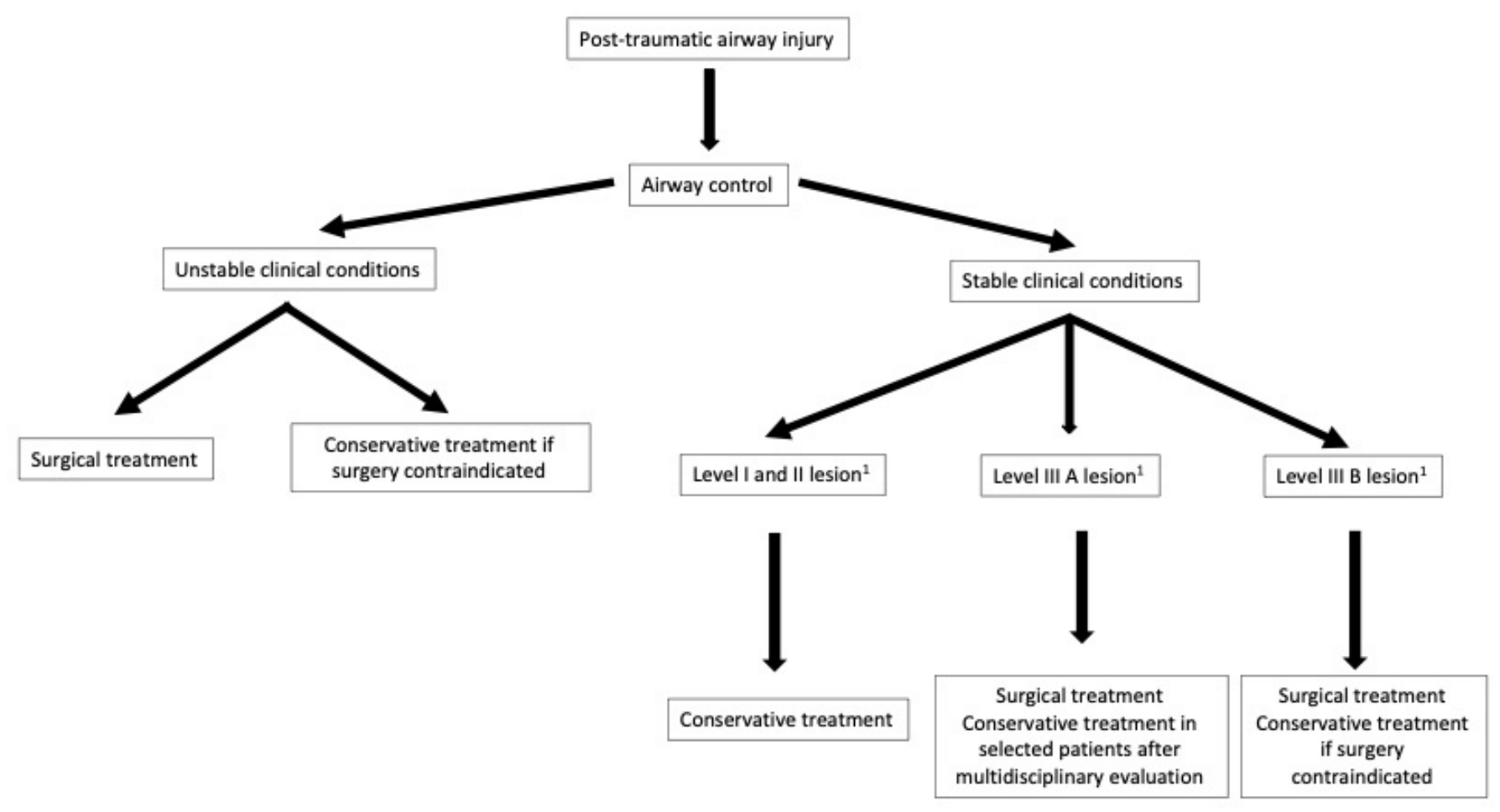

F I G U RE 2. Therapeutic strategy of post-traumatic airway lesions according to clinical and endoscopic features. See reference [46].

endoscopic features. Clinically stable patients with level I and II lesions may undergo observation, which is usually associated with broad-spectrum antibiotic therapy and endoscopic treatment with fibrin glue $[46,47]$. The use of preventive tracheotomy or minitracheotomy to reduce airway pressure and wound gaping during cough has been reported, but their role still has to be completely evaluated [48]. In patients requiring mechanical ventilation and with a contraindication to surgical treatment, an endotracheal tube or a tracheotomy cannula with the cuff distal to the lesion is positioned. Care should be taken to maintain the tube cuff inflated to the lowest sealing pressure required to maintain ventilaton, in order to reduce the risk of further airway damage. This is especially true in patients with nasogastric intubation, in whom a tracheoesophageal fistula may develop due to the compression and ischemia of the tracheal and esophageal walls between the endotracheal and nasogastric tubes [49]. After respiratory weaning, when a significant posterior esophageal bulging is observed, a Montgomery T-tube may replace the tracheostomy cannula to allow physiological phonation while healing of the injury is completed $[50,51]$. In the choice of conservative treatment, it is mandatory to bear in mind that surgical treatment may be a viable option for only 48 to 72 hours after the onset of the lesion. In fact, mortality associated with late surgical treatment is significantly higher due to sepsis, reduced vascularization of the lesion margins, and development of adhesions [52]. Pros and cons of a conservative treatment must therefore be carefully considered. This is particularly true in patients with full-thickness lesions of the airway and communication with the mediastinum, even without signs of infection or esophageal lesions. In this case the indication for conservative treatment should be taken into consideration only after a multidisciplinary evaluation, performed in a center with extensive experience in the treatment of airway lesions (Fig. 2) [53].

\section{Endoscopic treatment}

Conservative treatment of post-traumatic airway lesions with fibrin glue and tracheal or bronchial stents has been described [21, 46, 47, 54]. Self-expanding metallic stents are preferred by some authors since they more easily adapt to the shape of the tracheobronchial tree and more effectively seal the lesion, but care has to be taken to appropriately select the correct stent size to avoid enlargement of the injury [55-57]. Moreover, stent removal after healing may be rather demanding. Conversely, the use of silicon stents is associated with a higher risk of migration, and their use is typically limited to lesions involving the carinal region (Y-stents) or in patients bearing a tracheostomy (Montgomery T-tubes) [50, 58]. Granulation tissue formation, usually considered a drawback of airway stents, may facilitate healing of the lesion. Stenting of posttraumatic lesions is usually a temporary treatment, and the stents are removed after a few weeks or months once the lesion has successfully healed. Recently, endoscopic repair of longitudinal lesions of the membranous part of the trachea under rigid bronchoscopy has been reported. Welter et al. used a dedicated endoscopic needle holder to repair the tracheal lesion with a continuous absorbable suture, while Krassas et al. used a conventional endoscopic needle holder [59, 60]. Although the reduced invasiveness of this approach may be an advantage especially in frail patients, it may have significant limitations. It seems at present suitable only in the repair of longitudinal lesions of the membranous part of the 
trachea, since repair of bronchial lacerations may be impaired by the reduced size of the airway, which limits adequate movements of the instrumentation. Moreover, identification and mobilization of the lesion margins to complete the repair may be arduous, even in experienced hands. Anesthesiological critical issues concern the fact that the procedure is performed under jet ventilation and is therefore contraindicated in patients requiring other types of ventilation. Nevertheless, this approach may represent an alternative to surgery in selected patients with level IIIa lesions in stable clinical conditions.

\section{Surgical treatment}

Surgery remains the gold standard treatment in patients with unstable clinical features, inadequate respiratory parameters, worsening pneumomediastinum, persistent air leaks, risk of infection due to communication with the mediastinum, and associated pulmonary, esophageal, or vascular lesions. The surgical approach is selected on the basis of a careful endoscopic and radiological assessment, which should not only determine the extension and characteristics of the lesions but also clearly show their location. Accurately determining whether the lesion is in the cervical or mediastinal region is essential to correctly choosing the surgical approach and completing treatment [36]. A tranverse or left cervicotomy is the standard incision for lesions of the proximal two-thirds of the trachea, associated with a partial sternotomy when the lesion extends to the middle trachea. A left cervical approach may be indicated in case of combined airway and esophageal lesions, although this approach is associated with a higher risk of recurrent laryngeal nerve palsy. The anterior transtracheal approach, described by Angelillo-Mackinlay and Lancelin, is associated with a reduced risk of recurrent nerve damage and may be successfully used in the treatment of lesions involving the upper two-thirds of the trachea, although contraindicated in the presence of associated esophageal lesions [61, 62]. The use of a bronchoscope during the procedure may aid in the visualization of lesions of the distal part of the airway. Injuries of the lower third of the trachea are better treated through a right thoracotomy in the fourth intercostal space, sectioning the azygos vein to allow optimal exposure, and a thoracotomy on the side of the lesion is required in the presence of bronchial disruptions. The use of a transmediastinal approach through a sternotomy has also been described in the treatment of lesions in the carinal region, especially if associated with vascular lesions. The use of a clamshell approach has also been reported, but its use is limited to the treatment of airway lesions associated with major cardiovascular or pulmonary trauma $[14,15]$.

The technique of repair should be adapted to the specific characteristics of the lesion. End-to-end reconstruction is indicated in case of complete separation of the airway or if extensive damage of the airway is observed. However, direct repair of the lesion with interrupted or continuous absorbable sutures with the knots tied outside the lumen is indicated in most cases (Figs. 3 and 4) [15]. Careful dissection and debridment of the lesion margins should be performed, avoiding devascularization. It must be taken into consideration that in patients with penetrating injuries due to bullets, the high

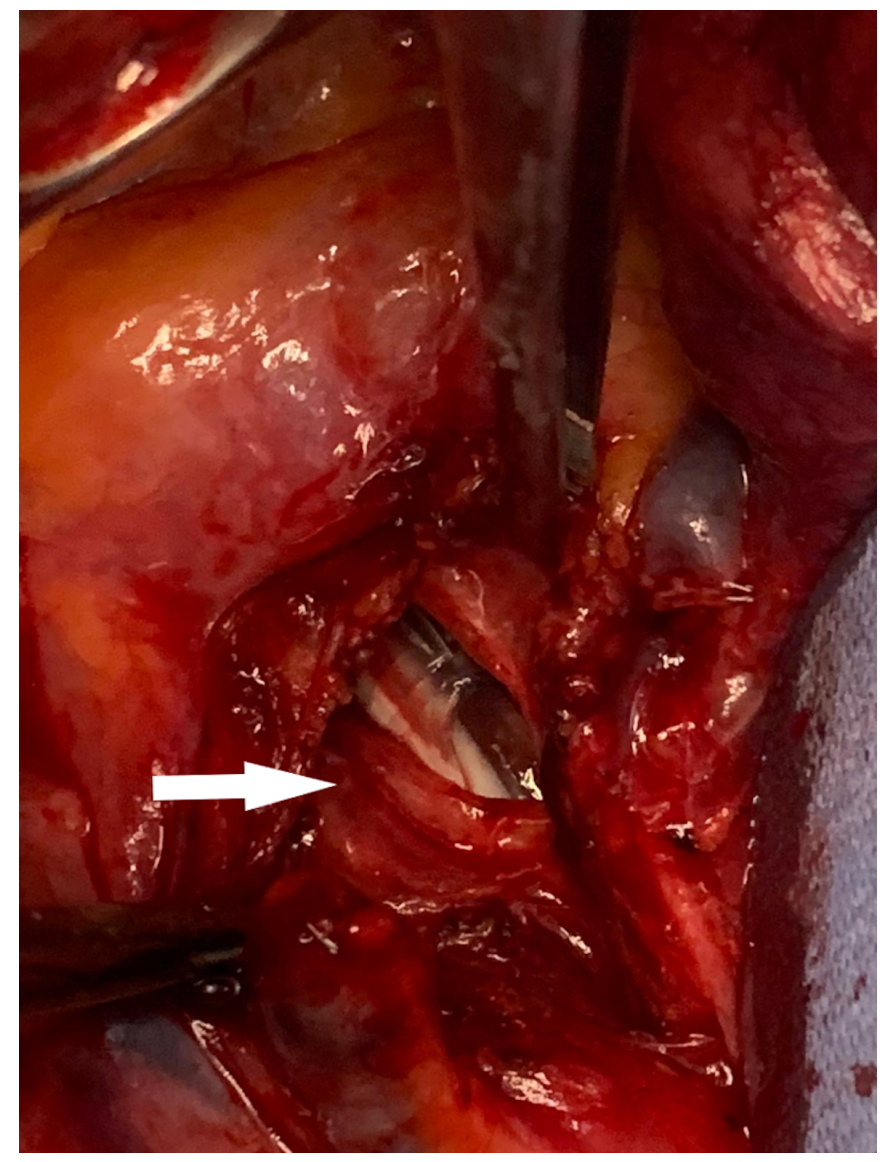

FIGURE 3. Operative view (right thoracotomy): intrathoracic post-intubation tracheal injury (arrow).

energy of the penetrating object may extend the devitalization of the airway beyond the visible margins of the lesion [63]. Whenever direct repair cannot be accomplished or when major pulmonary lesions are associated to the airway lesion, anatomical lung resections may be required [6]. Some authors advise buttressing the suture with viable tissue, such as pericardial fat pad or pedicled intercostal and cervical strap muscles, particularly if the patient cannot be extubated soon after the procedure or in the presence of poorly vascularized lesion margins [7]. A tracheostomy, performed at least $1 \mathrm{~cm}$ away from the suture line to avoid ischemia and dehiscence, may be indicated if laryngeal oedema or recurrent laryngeal nerve lesions are present [64]. In patients submitted to tracheal endto-end reconstruction, whenever tension on the suture line is observed during surgery, a laryngeal or hilar release should be associated, and the patient's neck maintained in a flexed position in the first postoperative week. The reported perioperative mortality of a patient submitted to surgical treatment varies largely among the reported series and is significantly influenced by associated post-traumatic lesions or comorbidities. In particular, the need for a pneumonectomy in patients with major pulmonary lesions is associated with a significant increase of the mortality rate [65]. Acording to Leinung et al. the results are adversely influenced by the presence of mediastinitis, a longer interval of time between diagnosis and treatment and previous surgical procedures involving the mediastinum [66]. 
TA B L E 4. Techniques to maintain gas exchange during surgical treatment of post-traumatic airway lesions.

Cervicotomy approach

Cross-field ventilation

High-frequency jet ventilation (HFJV)

Extracorporeal membrane oxygenation (ECMO)

Thoracotomy approach

Cross-field ventilation

High frequency jet ventilation (HFJV)

Double-lumen tracheobronchial tube

Tracheal intubation and bronchial occlusion with endobronchial blockers

Intubation of the contralateral main bronchus with extra-long tube

Extracorporeal membrane oxygenation (ECMO)

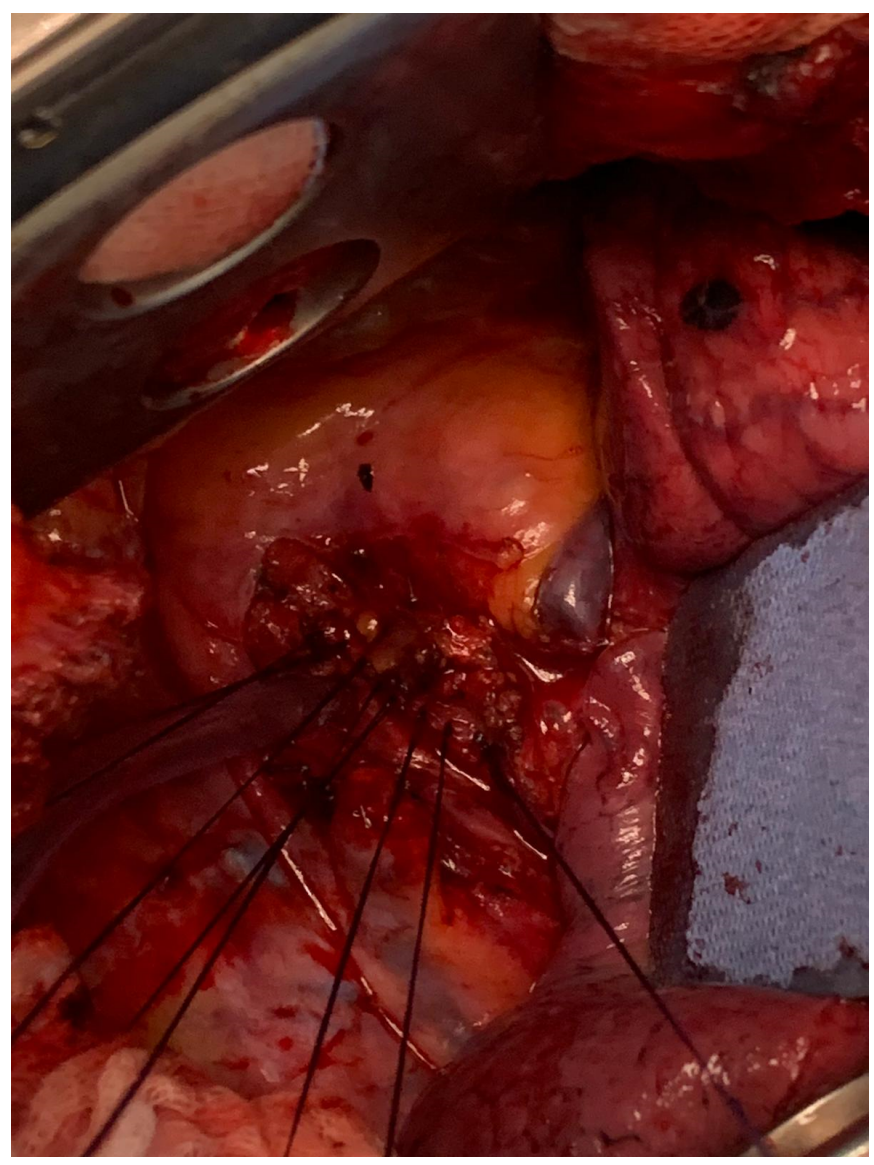

F I G U R E 4. Surgical repair of the lesion with interrupted absorbable suture.

\section{Anesthesia}

Prompt and accurate airway control is mandatory to save the lives of patients with airway lesions and allow adequate treatment to be accomplished. Whenever possible bronchoscopic intubation should be used to avoid further damage of the airway, especially when a total disruption of the airway is present [1]. The cuff of the endotracheal tube should be positioned distal to the lesion of the airway to correctly ventilate the patient. Different methods may be used to maintain adequate gas exchange during surgical treatment, while maintaining an adequate exposure of the surgical field. Strict cooperation between the anesthesiologist and the surgeon is of utmost importance in patients with airway lesions, especially in those with complex lesions and impaired respiratory function due to associated pulmonary lesions. Most tracheal lesions are repaired during cross-field ventilation with intermittent periods of apnea [67]. The use of high-frequency jet ventilation may be indicated when the endotracheal tube significantly impairs intraoperative visualization of the airway. However, its use is associated with a higher risk of hypercapnia and has specific limitations in obese patients and in case of reduced lung compliance [68]. When one-lung ventilation is required for the treatment of intrathoracic lesions, it may be obtained with bronchial blockers, double-lumen tracheobronchial tubes or by intubating the contralateral main bronchus with an extra-long bronchial tube. In patients with a contusion of the dependent lung, unilateral ventilation must be limited to short periods to maintain adequate gas exchange and prevent acidosis. In the treatment of patients with intrathoracic lesions, the correct position of the endotracheal tube should be endoscopically verified before the mediastinal pleura is opened. In fact, an intact pleura may limit air leaks during mechanical ventilation even if the tube is incorrectly positioned, and a sudden loss of ventilation may happen as soon as the mediastinal space is opened. Significant ventilation problems may also arise in the presence of lesions near the carina, since positioning the tube of the endotracheal tube beyond the lesion while maintaining effective ventilation may not be possible. In these circumstances, and when intubation of the distal airway due to complete separation cannot be safely accomplished, ECMO may be indicated, despite a higher risk of bleeding and of iatrogenic vascular lesions [69-71]. Another possible indication for ECMO is inadequate oxygenation due to major post-traumatic pulmonary lesions. Veno-venous ECMO is used in patients with preserved cardiac function, and venoarterial ECMO or CPB (cardiopulmonary bypass) is used in the presence of associated cardiac lesions or when the heart has to be moblilized during repair of complex airway lesions [72, 73]. Another major advantage of ECMO is that it may allow early extubation, reducing the trauma due to endotracheal tube on the site of trachobronchial repair (Table 4). 


\section{Late presentation}

Post-traumatic tracheobronchial injuries may not be diagnosed at the time of the acute event and have a delayed clinical presentation days or weeks after the trauma $[12,74,75]$. This may happen in patients with partial lesions of the airway or when the lesion is buttressed by surrounding cervical or mediastinal tissue, with adequate ventilation maintained throughout the healing process. The late onset of symptoms is mainly due to the repair process, leading to a cicatricial stenosis. Rarely, delayed presentation of complex lesions as tracheoesophageal fistulas is observed, with a diagnosis usually obtained following persistent cough and recurrent pulmonary infections. The diagnostic and therapeutic approach to delayed lesions is similar to that of postintubation stenosis of the airway, and airway resection and reconstruction may be indicated once acute inflammation has subsided [67]. Tracheobronchial stents may be used in patients with a contraindication to surgical treatment or as a temporary approach before surgery. Treatment of tracheoesophageal fistulas consists of esophageal and airway reconstruction, associated with muscle interposition between the esophagus and the trachea to prevent recurrence [49]. An airway lesion must be suspected in patients who develop respiratory symptoms after major trauma even late after the event. However, it has to be considered that most delayed posttraumatic airway lesions are due to post-intubation stenosis rather than to the trauma itself.

\section{Conclusions}

Post-traumatic tracheobronchial lesions are relatively rare events, associated with high mortality unless a prompt diagnosis and an accurate treatment are accomplished. A high degree of suspicion is therefore of utmost importance. Bronchoscopy has a main role in confirming the presence of an airway lesion and in the definition of the therapeutic strategy. In recent years conservative treatment, differentiated on the basis of endoscopic features, has been increasingly proposed. However, indications for conservative or surgical treatment have to be defined not only on the basis of endoscopic features but also according to clinical and radiological parameters. This is particularly true in lesions due to blunt and penetrating trauma, which often have complex characteristics and are associated with other post-traumatic injuries, which are issues that have a significant impact on mortality. In the treatment of such lesions, therefore, surgery still has a major role. A conservative approach may on the other hand be more frequently indicated in the treatment of iatrogenic lesions, although surgical treatment is still indicated in case of full-thickness airway lesions with a wide communication with the mediastinum. Full-thickness lesions with minor mediastinal communication and no signs of mediastinal infection require a multidisciplinary evaluation performed by experts in the field of airway treatment to define the optimal treatment. In this case the indication for conservative treatment has to be carefully weighed, since the results of surgical treatment after failure of a conservative approach are extremely poor, and postoperative mortality is markedly increased when surgical treatment is performed late and after the onset of signs of infection. Strict cooperation between anesthesiologist, endoscopist, and surgeon is of utmost importance during airway management, in the emergency setting, and intraoperatively to reduce mortality. Advanced techniques such as ECMO may be indicated in patients who cannot be successfully ventilated or in those with associated pulmonary or cardiovascular lesions and may allow to push forward the indications for the treatment of post-traumatic airway lesions.

\section{AUTHOR CONTRIBUTIONS}

Angelo Carretta analyzed the data, wrote and drafted the manuscript; Paola Ciriaco analyzed the data and drafted the manuscript; Alessandro Bandiera collected and analyzed the data; Giampiero Negri drafted the manuscript.

\section{ACKNOWLEDGMENT}

We thank Judy Wilson for editing the manuscript.

\section{CONFLICT OF INTEREST}

The authors declare that there is no conflict of interest regarding the publication of this article.

\section{REFERENCES}

[1] Cassada DC, Munyikwa MP, Moniz MP, Dieter RA Jr, Schuchmann GF, Enderson BL. Acute injuries of the trachea and main bronchi: importance of early diagnosis. The Annals of Thoracic Surgery. 2000; 69: 1563-1567.

[2] Minard G, Kudsk KA, Croce MA, Butts JA, Cicala RS, Fabian TC. Laryngotracheal trauma. The American Surgeon. 1992; 58: 181-187.

[3] Kummer C, Netto FS, Rizoli S, Yee D. A review of traumatic airway injuries: potential implications for airway assessment and management. Injury. 2007; 38: 27-33.

[4] Bertelsen S, Howitz P. Injuries of the trachea and bronchi. Thorax. 1972; 27: 188-194.

[5] Schneider T, Volz K, Dienemann H, Hoffmann H. Incidence and treatment modalities of tracheobronchial injuries in Germany. Interactive CardioVascular and Thoracic Surgery. 2009; 8: 571-576.

[6] Baumgartner F, Sheppard B, de Virgilio C, Esrig B, Harrier D, Nelson RJ, et al. Tracheal and main bronchial disruptions after blunt chest trauma: presentation and management. The Annals of Thoracic Surgery. 1990; 50: 569-574.

[7] Rossbach MM, Johnson SB, Gomez MA, Sako EY, Miller OL, Calhoon JH. Management of major tracheobronchial injuries: a 28-year experience. The Annals of Thoracic Surgery. 1998; 65: 182-186.

[8] Gómez-Caro A, Ausín P, Moradiellos FJ, Díaz-Hellín V, Larrú E, Pérez $\mathrm{JA}$, et al. Role of conservative medical management of tracheobronchial injuries. The Journal of Trauma. 2006; 61: 1426-1434.

[9] Chu CPW, Chen PP. Tracheobronchial injury secondary to blunt chest trauma: diagnosis and management. Anaesthesia and Intensive Care. 2002; 30: 145-152.

[10] Wu M, Tsai Y, Lin M, Hsu I, Fong Y. Complete laryngotracheal disruption caused by blunt injury. The Annals of Thoracic Surgery. 2004; 77: 12111215 .

[11] Norwood SH, McAuley CE, Vallina VL, Berne JD, Moore WL. Complete cervical tracheal transection from blunt trauma. The Journal of Trauma. 2001; 51: 568-571.

[12] Kiser AC, O'Brien SM, Detterbeck FC. Blunt tracheobronchial injuries: treatment and outcomes. The Annals of Thoracic Surgery. 2001; 71: 2059-2065.

[13] Kirsh MM, Orringer MB, Behrendt DM, Sloan H. Management of 
tracheobronchial disruption secondary to nonpenetrating trauma. The Annals of Thoracic Surgery. 1976; 22: 93-101.

[14] Balci AE, Eren N, Eren S, Ulkü R. Surgical treatment of post-traumatic tracheobronchial injuries: 14-year experience. European Journal of Cardio-Thoracic Surgery. 2002; 22: 984-989.

[15] Lyons JD, Feliciano DV, Wyrzykowski AD, Rozycki GS. Modern management of penetrating tracheal injuries. The American Surgeon. 2013; 79: 188-193.

[16] Miñambres E, Burón J, Ballesteros MA, Llorca J, Muñoz P, GonzálezCastro A. Tracheal rupture after endotracheal intubation: a literature systematic review. European Journal of Cardio-Thoracic Surgery. 2009; 35: 1056-1062.

[17] Ceylan KC, Kaya SO, Samancilar O, Usluer O, Gursoy S, Ucvet A. Intraoperative management of tracheobronchial rupture after doublelumen tube intubation. Surgery Today. 2013; 43: 757-762.

[18] Massard G, Rougé C, Dabbagh A, Kessler R, Hentz JG, Roeslin N, et al. Tracheobronchial lacerations after intubation and tracheostomy. The Annals of Thoracic Surgery. 1996; 61: 1483-1487.

[19] Warner MA, Fox JF. Direct laryngoscopy and endotracheal intubation complicated by anterior tracheal laceration secondary to protrusion of preloaded endotracheal tube stylet. Case Reports. 2016; 6: 77-79.

[20] Marty-Ané CH, Picard E, Jonquet O, Mary H. Membranous tracheal rupture after endotracheal intubation. The Annals of Thoracic Surgery. 1995; 60: 1367-1371.

[21] Grewal HS, Dangayach NS, Ahmad U, Ghosh S, Gildea T, Mehta AC. Treatment of tracheobronchial injuries. Chest. 2019; 155: 595-604.

[22] Symbas PN, Justicz AG, Ricketts RR. Rupture of the airways from blunt trauma: treatment of complex injuries. The Annals of Thoracic Surgery. 1992; 54: 177-183.

[23] Gosnell JE, Campbell P, Sidhu S, Sywak M, Reeve TS, Delbridge LW. Inadvertent tracheal perforation during thyroidectomy. The British Journal of Surgery. 2006; 93: 55-56.

[24] Lui N, Wright C. Intraoperative tracheal injury. Thoracic Surgery Clinics. 2016; 25: 249-254.

[25] Kim JH, Shin JH, Song H, Shim TS, Ko G, Yoon H, et al. Tracheobronchial laceration after balloon dilation for benign strictures: incidence and clinical significance. Chest. 2007; 131: 1114-1117.

[26] Cosgrove JE, Sweenie A, Raftery G, Carey SM, Kilner AJ, Nesbitt ID, et al. Locally developed guidelines reduce immediate complications from percutaneous dilatational tracheostomy using the Ciaglia Blue Rhino technique: a report on 200 procedures. Anaesthesia and Intensive Care. 2006; 34: 782-786.

[27] Trottier SJ, Hazard PB, Sakabu SA, Levine JH, Troop BR, Thompson JA, et al. Posterior tracheal wall perforation during percutaneous dilational tracheostomy: an investigation into its mechanism and prevention. Chest. 1999; 115: 1383-1389.

[28] Winkler WB, Karnik R, Seelmann O, Havlicek J, Slany J. Bedside percutaneous dilational tracheostomy with endoscopic guidance: experience with 71 ICU patients. Intensive Care Medicine. 1994; 20: 476-479.

[29] Maxwell BG, Ganaway T, Lighthall GK. Percutaneous tracheostomy at the bedside: 13 tips for improving safety and success. Journal of Intensive Care Medicine. 2014; 29: 110-115.

[30] Dennis BM, Eckert MJ, Gunter OL, Morris JA, May AK. Safety of bedside percutaneous tracheostomy in the critically ill: evaluation of more than 3,000 procedures. Journal of the American College of Surgeons. 2013; 216: 858-857.

[31] Bagga B, Kumar A, Chahal A, Gamanagatti S, Kumar S. Traumatic airway injuries: role of imaging. Current Problems in Diagnostic Radiology. 2020; 49: 48-53.

[32] Wilkerson RG, Stone MB. Sensitivity of bedside ultrasound and supine anteroposterior chest radiographs for the identification of pneumothorax after blunt trauma. Academic Emergency Medicine. 2010; 17: 11-17.

[33] Savaş R, Alper H. Fallen lung sign: radiographic findings. Diagnostic and Interventional Radiology. 2008; 14: 120-121.

[34] Chen JD, Shanmuganathan K, Mirvis SE, Killeen KL, Dutton RP. Using CT to diagnose tracheal rupture. American Journal of Roentgenology. 2001; 176: 1273-1280.

[35] Barnhart GR, Brooks JW, Kellum JM. Pneumoperitoneum resulting from tracheal rupture following blunt chest trauma. The Journal of Trauma. 1986; 26: 486-488.
[36] Koletsis E, Prokakis C, Baltayiannis N, Apostolakis E, Chatzimichalis A, Dougenis D. Surgical decision making in tracheobronchial injuries on the basis of clinical evidences and the injury's anatomical setting: a retrospective analysis. Injury. 2012; 43: 1437-1441.

[37] Verschueren DS, Bell RB, Bagheri SC, Dierks EJ, Potter BE. Management of laryngo-tracheal injuries associated with craniomaxillofacial injuries. Journal of Oral and Maxillofacial Surgery. 2006; 64: 203-214.

[38] Bonanno FG. Issues of critical airway management (which anesthesia; which surgical airway?). Journal of Emergencies, Trauma, and Shock. 2012; 5: 279-284.

[39] Ono Y, Yokoyama H, Matsumoto A, Kumada Y, Shinohara K, Tase C. Surgical airways for trauma patients in an emergency surgical setting: 11 years' experience at a teaching hospital in Japan. Journal of Anesthesia. 2013; 27: 832-837.

[40] Naghibi K, Hashemi L, Sajedi P. Anesthetic management of tracheobronchial rupture following blunt chest trauma. Acta Anaesthesiologica Scandinavica. 2003; 47: 901-903.

[41] Conti M, Pougeoise M, Wurtz A, Porte H, Fourrier F, Ramon P, et al. Management of postintubation tracheobronchial ruptures. Chest. 2006; 130: 412-418

[42] Carretta A, Ciriaco P, Bandiera A, Muriana P, Pappalardo F, Broman LM, et al. Veno-venous extracorporeal membrane oxygenation in the surgical management of post-traumatic intrathoracic tracheal transection. Journal of Thoracic Disease. 2018; 10: 7045-7051.

[43] Carbognani P, Bobbio A, Cattelani L, Internullo E, Caporale D, Rusca M. Management of postintubation membranous tracheal rupture. The Annals of Thoracic Surgery. 2004; 77: 406-409.

[44] Harris R, Joseph A. Acute tracheal rupture related to endotracheal intubation: case report. The Journal of Emergency Medicine. 2000; 18: 35-39.

[45] Ross HM, Grant FJ, Wilson RS, Burt ME. Nonoperative management of tracheal laceration during endotracheal intubation. The Annals of Thoracic Surgery. 1997; 63: 240-242.

[46] Cardillo G, Carbone L, Carleo F, Batzella S, Jacono RD, Lucantoni $\mathrm{G}$, et al. Tracheal lacerations after endotracheal intubation: a proposed morphological classification to guide non-surgical treatment. European Journal of Cardio-Thoracic Surgery. 2010; 37: 581-587.

[47] Herrmann D, Volmerig J, Al-Turki A, Braun M, Herrmann A, Ewig S, et al. Does less surgical trauma result in better outcome in management of iatrogenic tracheobronchial laceration? Journal of Thoracic Disease. 2019; 11: 4772-4781.

[48] Massard G, Whilm JM. Decompressing tracheostomy for the treatment of postintubation tracheal rupture. The Annals of Thoracic Surgery. 1999; 68: $1125-1126$

[49] Reed MF, Mathisen DJ. Tracheoesophageal fistula. Chest Surgery Clinics of North America. 2003; 13: 271-289.

[50] Cooper JD, Todd TR, Ilves R, Pearson FG. Use of silicone tracheal T tube for the management of complex tracheal injuries. The Journal of Thoracic and Cardiovascular Surgery. 1981; 82: 559-68.

[51] Carretta A, Melloni G, Bandiera A, Negri G, Voci C, Zannini P. Conservative and surgical treatment of acute posttraumatic tracheobronchial injuries. World Journal of Surgery. 2011; 35: 2568-2574.

[52] Lampl L. Tracheobronchial injuries. Conservative treatment. Interactive Cardiovascular and Thoracic Surgery. 2004; 3: 401-405.

[53] Lee SK, Kim DH, Lee SK, Kim Y, Cho JS, I H. Does surgical repair still have a role for iatrogenic tracheobronchial rupture? Clinical analysis of a thoracic surgeon's opinion. Annals of Thoracic and Cardiovascular Surgery. 2016; 22: 348-353.

[54] Tazi-Mezalek R, Musani AI, Laroumagne S, Astoul PJ, D’Journo XB, Thomas PA, et al. Airway stenting in the management of iatrogenic tracheal injuries: 10-year experience. Respirology. 2016; 21: 1452-1458.

[55] Lee BE, Korst RJ. Successful treatment of an iatrogenic tracheal laceration with a temporary polyurethane-coated nitinol stent. The Annals of Thoracic Surgery. 2016; 102: e11-e12.

[56] Mughal MM, Gildea TR, Murthy S, Pettersson G, DeCamp M, Mehta AC. Short-term deployment of self-expanding metallic stents facilitates healing of bronchial dehiscence. American Journal of Respiratory and Critical Care Medicine. 2005; 172: 768-771.

[57] Shemmeri E, Vallières E. Blunt tracheobronchial trauma. Thoracic Surgery Clinics. 2018; 28: 429-434. 
[58] Yamamoto S, Endo S, Endo T, Mitsuda S. Successful silicon stent for life-threatening tracheal wall laceration. Annals of Thoracic and Cardiovascular Surgery. 2013; 19: 49-51.

[59] Welter S, Krbek T, Halder R, Stamatis G. A new technique for complete intraluminal repair of iatrogenic posterior tracheal lacerations. Interactive CardioVascular and Thoracic Surgery. 2011; 12: 6-9.

[60] Krassas A, Mallios D, Iliadis I, Agiannidou A, Boulia S, Iliadis K. Bronchoscopical repair of tracheal laceration using conventional instrumentation: a novel technique. The Annals of Thoracic Surgery. 2020; 109: e141-e143.

[61] Angelillo-Mackinlay T. Transcervical repair of distal membranous tracheal laceration. The Annals of Thoracic Surgery. 1995; 59: 531-532.

[62] Lancelin C, Chapelier AR, Fadel E, Macchiarini P, Dartevelle PG. Transcervical-transtracheal endoluminal repair of membranous tracheal disruptions. The Annals of Thoracic Surgery. 2000; 70: 984-986.

[63] Sulek M, Miller RH, Mattox KL. The management of gunshot and stab injuries of the trachea. Archives of Otolaryngology. 1983; 109: 56-59.

[64] Mathisen DJ, Grillo H. Laryngotracheal trauma. The Annals of Thoracic Surgery. 1987; 43: 254-262.

[65] Richardson JD. Outcome of tracheobronchial injuries: a long-term perspective. The Journal of Trauma. 2004; 56: 30-36.

[66] Leinung S, Möbius C, Hofmann H, Ott R, Rüffert H, Schuster E, et al. Iatrogenic tracheobronchial ruptures-treatment and outcomes. Interactive Cardiovascular and Thoracic Surgery. 2006; 5: 303-306.

[67] Grillo HC, Donahue DM, Mathisen DJ, Wain JC, Wright CD. Postintubation tracheal stenosis. Treatment and results. The Journal of Thoracic and Cardiovascular Surgery. 1995; 109: 486-483.

[68] Chitilian HV, Bao X, Mathisen DJ, Alfille PH. Anesthesia for airway surgery. Thoracic Surgery Clinics. 2018; 28: 249-255.

[69] Chang X, Zhang X, Li X, Xu M, Zhao H, Fang W, et al. Use of extracorporeal membrane oxygenation in tracheal surgery: a case series.
Perfusion. 2014; 29: 159-162.

[70] Son BS, Cho WH, Kim CW, Cho HM, Kim SH, Lee SK, et al. Conservative extracorporeal membrane oxygenation treatment in a tracheal injury: a case report. Journal of Cardiothoracic Surgery. 2015; 10: 48.

[71] Sian K, McAllister B, Brady P. The use of extracorporeal membrane oxygenation therapy in the delayed surgical repair of a tracheal injury. The Annals of Thoracic Surgery. 2014; 97: 338-340.

[72] Hirsh J, Gollin G, Seashore J, Kopf G, Barash PG. Mediastinal "tamponade" of a tracheal rupture in which partial cardiopulmonary bypass was required for surgical repair. Journal of Cardiothoracic and Vascular Anesthesia. 1994; 8: 682-684.

[73] Pasic M, Ewert R, Engel M, Franz N, Bergs P, Kuppe H, et al. Aortic rupture and concomitant transection of the left bronchus after blunt chest trauma. Chest. 2000; 117: 1508-1510.

[74] Demir A, Olcmen A, Kara H, Dincer S. Delayed diagnosis of a complete bronchial rupture after blunt thoracic trauma. The Thoracic and Cardiovascular Surgeon. 2006; 54: 560-562.

[75] Glazer ES, Meyerson SL. Delayed presentation and treatment of tracheobronchial injuries due to blunt trauma. Journal of Surgical Education. 2008; 65: 302-308.

[76] Schneider T, Storz K, Dienemann H, Hoffmann H. Management of iatrogenic tracheobronchial injuries: a retrospective analysis of 29 cases. The Annals of Thoracic Surgery. 2007; 83: 1960-1964.

How to cite this article: Angelo Carretta, Paola Ciriaco, Alessandro Bandiera, Giampiero Negri. Diagnostic and therapeutic approach to post-traumatic tracheobronchial injuries. Signa Vitae. 2021;17(2):1019. doi:10.22514/sv.2021.015. 